\title{
Development of New Mouse Breast Cancer Model of Local Bone Metastasis and Verification Using Bisphosphonates
}

\author{
RYO SHOJI, HIROYUKI TSUCHIE, HIROYUKI NAGASAWA, MICHIO HONGO, \\ YUJI KASUKAWA, DAISUKE KUDO and NAOHISA MIYAKOSHI \\ Department of Orthopedic Surgery, Akita University Graduate School of Medicine, Akita, Japan
}

\begin{abstract}
Background/Aim: Local tumor injection models require complicated procedures. The purpose was to establish a simple local bone metastasis model using normal mice, and to study the usefulness of the model with bisphosphonates (BP). Materials and Methods: This study used a versatile C57BL/6 mouse model and E0771 cells. Tumor cells were injected into the right femur. Mice were divided into groups depending on the concentration of cells injected and the use of BP or not. The degree of bone destruction between the different conditions was compared using micro-computed tomography $(\mu C T)$. Results: Bone destruction was confirmed in four mice in the highconcentration group at 3 weeks, and in all other mice at 4 and 6 weeks. At 6 weeks post-injection, bone destruction was significantly suppressed in the BP group $(p<0.05)$. Conclusion: We created a breast cancer mouse model of local bone metastasis. Zoledronate showed the same usefulness as in previous models. It may be an effective model for evaluating treatments for bone metastasis.
\end{abstract}

In 2018, 18 million cancer patients and 9.6 million cancer deaths were reported globally (1). In addition, more than 20 million new cancer cases are expected in 2025, mainly in developing countries (2). In Japan, 370,000 patients died of cancer in 2019 (3). The 5-year survival rate of cancer patients is increasing because of new drugs - mainly, molecular targeted drugs and immune checkpoint inhibitors and advances in treatment, such as improved surgical techniques (4). Bone metastasis is a common complication

This article is freely accessible online.

Correspondence to: Ryo Shoji, Department of Orthopedic Surgery, Akita University Graduate School of Medicine, 1-1-1 Hondo, Akita 010-8543, Japan. Tel: +81 188846148, Fax: +81 188362617, e-mail: yebyayayeby@gmail.com

Key Words: Metastasis, breast, bisphosphonates. of advanced cancer. The increase in the survival rate of patients with carcinoma suggests the possibility of an increase in the number of patients with bone metastasis. Breast cancer is the most common cancer among women and the leading cause of cancer-related deaths among women in Japan and the United States $(5,6)$. Bone is one of the most common metastatic sites in advanced breast cancer, and bone metastasis is clinically problematic because it causes a variety of adverse bone-related events.

The mechanisms underlying bone metastasis are not fully elucidated. Animal models are essential for investigating the disease mechanisms and drug effects. However, in rodents and small animals, both the spontaneous occurrence of cancer (7) and cases of metastasis are rare (8). Therefore, it is important to create bone metastasis models; most of which are established by transvenous administration, thus, mimicking the hematogenous metastasis (9). Using this method, however, it is difficult to localize bone metastases. There have been reports of inducing bone metastases only in the target bone by injecting tumor cells directly into the medullary cavity (10). This method, however, has not been widely used owing to its complicated handling in terms of infection.

In this study, we attempted to create a distant metastasis model of the mouse breast cancer cell line E0771 (11-12) in the femur using a versatile C57BL/6 mouse model. We verified the usefulness of this model using bone resorption inhibitors, have been shown to be useful in a mouse model of systemic administration (13). Our second aim was to assess whether we could confirm the efficacy of the bone resorption inhibitor, making this model useful for drug therapy in bone metastases.

\section{Materials and Methods}

Cell culture. E0771 (CH3 Biosystems LLC, NY) cells were cultured in Dulbecco's modified Eagle's medium (Sigma-Aldrich, St. Louis, MO, USA) supplemented with $10 \%$ fetal bovine serum (Mediatech, Manassas, VA, USA) and $100 \mu \mathrm{g} / \mathrm{ml}$ kanamycin sulfate (Meiji Seika Pharma, Tokyo, Japan). These were maintained in a humidified atmosphere of $5 \% \mathrm{CO}_{2}$ in air and $37^{\circ} \mathrm{C}(14)$. The cells were verified 
to be mycoplasma-free before mouse injections using a PCR-based method (ICLAS Monitoring Center, Kawasaki, Japan).

The cells were diluted in phosphate-buffered saline (PBS) so that the final number of cells was either $1.0 \times 10^{4} / 10 \mu 1$ or $1.0 \times 10^{5 / 10 \mu l}$. The survival rate of the tumor cells was evaluated using the trypan blue dye exclusion method with a hemocytometer (Kayagaki, Tokyo, Japan) under an optical microscope (Olympus BH-210, Tokyo, Japan $\times 400$ ).

Animal experiments. Four-week-old female C57BL/6 mice (Charles River Laboratory Inc., Kanagawa, Japan) were housed in a specific pathogen-free environment. The mice were anesthetized, and E0771 cells were administered topically. In detail, a combination anesthetic was prepared with $0.3 \mathrm{mg} / \mathrm{kg}$ of medetomidine, 4.0 $\mathrm{mg} / \mathrm{kg}$ of midazolam, and $5.0 \mathrm{mg} / \mathrm{kg}$ of butorphanol and administered via subcutaneous injection to obtain a good depth of anesthesia. We made a median incision in the knee of each mouse, and the patella was flipped laterally to expose the femoral condyle. We created a bone socket in the femur using a $26 \mathrm{G}$ needle. Different concentrations of E0771 cells $\left(1.0 \times 10^{4 / 10 \mu l ~ \& ~}\right.$ $1.0 \times 10^{5} / 10 \mu \mathrm{l}$ ) were suspended in $10 \mu \mathrm{l}$ of PBS injected using a Hamilton syringe (Figure 1). The mice were divided into two groups: i) a high concentration group injected with $1.0 \times 10^{5 / 10} \mu \mathrm{l}$ tumor cells $(\mathrm{n}=4)$ and ii) a low concentration group injected with $1.0 \times 10^{4} / 10 \mu$ tumor cells $(n=4)$. The mice were kept for 6 weeks before being sacrificed. The development of bone metastases was monitored by micro-computed tomography $(\mu \mathrm{CT})$ analysis using micro-focus X-ray computed tomography CosmoScan GX II (Rigaku Corporation, Tokyo, Japan). Three-dimensional digital images were reconstructed using the bone analysis software (Rigaku Corporation, Tokyo, Japan). The mice were monitored at 3,4 , and 6 weeks post-injection, and the degree of bone destruction was calculated. To calculate the rate of bone destruction using $\mu \mathrm{CT}$, we first measured the length of the femur from the femoral head to the femoral condyle in the sagittal section. The axial section was used to identify the location where cortical bone destruction was partially observed, and the sagittal section was used to confirm the length of bone destruction. The following calculation method was used: femur length with the appearance of bone destruction/femur length $\times 100$. The appearance of metastasis was confirmed by $\mu \mathrm{CT}$ after sacrifice.

In the next experiment, the mice injected with the high concentration of E0771 cells were randomly divided into two groups: i) control group $(n=10)$ and ii) bisphosphonate (BP) group $(\mathrm{n}=10)$. The BP group received zoledronic acid $(\mathrm{ZOL})$ at $100 \mu \mathrm{g} / \mathrm{kg}$ subcutaneously 2 weeks after the administration of E0771 cells, and they were sacrificed after 6 weeks of captivity. A dose of $100 \mu \mathrm{g} / \mathrm{kg}$ $\mathrm{ZOL}$ was equivalent to a $4 \mathrm{mg}$ infusion used for the treatment of bone metastasis in humans (15).

Two groups were monitored at 3, 4, and 6 weeks post-injection, and the bone destruction rates were calculated. The appearance of metastasis was confirmed by $\mu \mathrm{CT}$ after sacrifice. The right thigh and tumor were removed as a single mass, and tumor volume and weight were measured. Calipers were used to obtain volume measurements.

The protocols for the animal experiments described in this paper were previously approved by the Animal Research Committee, Akita University School of Medicine, and all subsequent animal experiments adhered to the "Guidelines for Animal Experimentation" of the University.
Statistical analysis. Data are expressed as the mean \pm standard deviation, and comparisons between two groups were analyzed by Student's $t$-test (R Development Core Team (2013) in R language and environment for statistical computing ( $R$ Foundation for Statistical Computing, Vienna, Austria). Significance was set at $p<0.05$.

\section{Results}

MicroCT at 3 weeks after tumor cell injection showed that cortical bone destruction was not observed in any of the mice in the low concentration group. However, cortical bone destruction was observed in all mice in the high concentration group. In addition, $\mu \mathrm{CT}$ at 4 and 6 weeks revealed visible bone destruction in all the mice from both groups (Table I). At 6 weeks post-injection, no distant metastasis was observed in either group and no deaths occurred before sacrifice. No complications, such as infections, were observed.

After injection with $1.0 \times 10^{5}$ tumor cells $/ 10 \mu$, destruction of the cortical bone by the tumor was confirmed in all mice in the control and BP groups at 3 weeks. The 4-week bone destruction rate was not significantly different between the two groups, however, at 6 weeks the bone destruction rate was significantly higher in the BP group compared to the control $(p=0.04)$. The weight and volume of the right femoral tumor collected at the time of sacrifice were measured, and no significant differences in tumor weight or volume were observed between the two groups (Table II).

\section{Discussion}

Interventional studies for the treatment of regional metastatic bone lesions are still underreported. One of the main reasons for this is the lack of established local bone metastasis models. There have been many reports of intracardiac and intravascular administration approaches (16-18), and therapeutic intervention studies in systemic administration models have been conducted using bone resorption inhibitors (19). However, the systemic administration model has several disadvantages. First, the cancer progresses systemically; the animal itself is in a situation where it must be sacrificed before therapeutic intervention. Second, the method is not reproducible because bone metastases cannot be locally created. Therefore, it is difficult to evaluate local bone metastases in systemic administration, although it is possible to study the effect on the whole body. One model in which tumor cells are directly administered into the medullary cavity has been reported as a method to induce local bone metastases (10), however, there are only a few reports on this method. Most of these reports were using immunodeficient mouse models, such as knockout and nude mice. The C57BL/6 mouse is one of the most widely used mice globally and is very versatile (20). Previously, Hiraga et al. reported that the breast cancer cell line E0771 was 

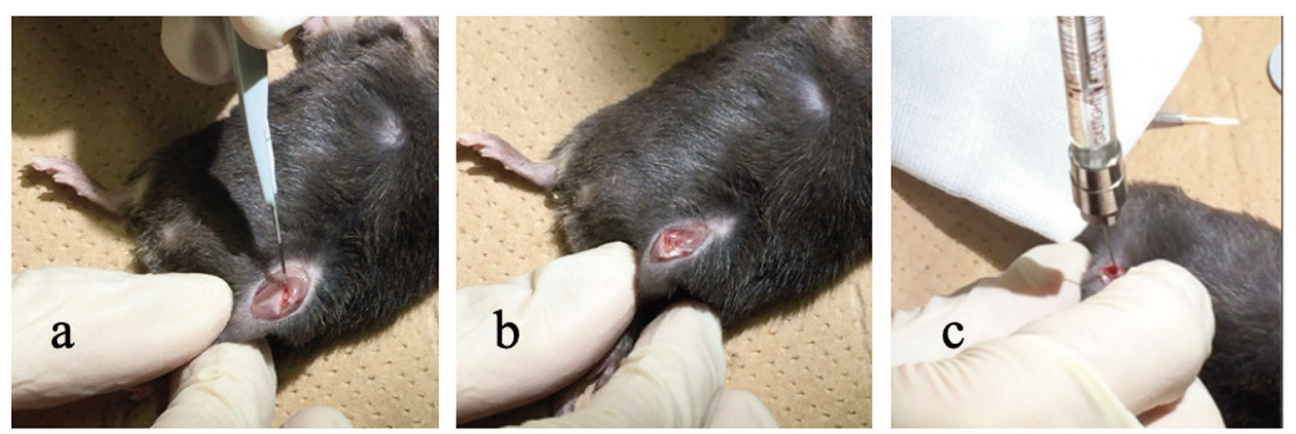

Figure 1. Tumor cell injection method. A midline incision was made in the mouse knee (a) followed by lateral dislocation of the patella to expose the femoral condyle (b). The bone was punctured with a $26 \mathrm{G}$ needle and the tumor cells were injected using a Hamilton syringe (c).

administered to C57BL/6 mice to establish a systemic bone metastasis model (14). Accordingly, we demonstrated that a local bone metastasis model can be generated by local administration of E0771 cells to the femurs of C57BL/6 mice. In addition, we used a previous report on the minimum concentration of tumor cells required for local bone metastasis models as a guide for selecting the concentration of tumor cells to be injected (10). By examining two groups with different tumor cell concentrations, we found that the high concentration group $\left(1.0 \times 10^{5}\right.$ cells $\left./ 10 \mu \mathrm{l}\right)$ was more reproducible as a bone metastasis model and more suitable for therapeutic intervention studies.

Our model has three main advantages. First, we can deliver exact quantities of tumor cells with controlled quality to a target site. The number of tumor cells reaching the local femoral bone marrow cavity can be strictly measured after excluding dead cells. Eliminating differences in the number of tumor cells injected into mice reduces the bias in judging the effectiveness of therapeutic interventions. Second, the technique is simple and reproducible, and the tumors appear consistently. This method of approaching the femur through the mid-knee incision by dislocating the patella outward can be employed in a few sessions, making it a stable technique. For the injection and bone hole methods, we determined that the Hamilton syringe approach is suitable based on a previous report (21). Finally, and most importantly, tumor appearance could be confirmed by $\mu \mathrm{CT}$ at a relatively early stage, i.e., 3 weeks after cell inoculation. In addition, it is possible to continue raising the animals without complications, such as infection, for 3 weeks after the initial intervention. The 3-week period after confirmation of tumor appearance makes it easier to confirm the effect of the intervening drugs on the appearance of local bone metastatic lesions.

$\mathrm{ZOL}$ is a standard therapeutic agent for bone metastases and has been proposed to have direct or indirect antitumor effects in vivo (13). Furthermore, when administered as adjuvant therapy added on the standard therapy, ZOL has been shown
Table I. Comparison of tumor appearance between high and low concentration groups.

\begin{tabular}{lcc}
\hline & $\begin{array}{c}\text { High } \\
\text { concentration } \\
\text { group (\%) }\end{array}$ & $\begin{array}{c}\text { Low } \\
\text { concentration } \\
\text { group (\%) }\end{array}$ \\
\hline $\begin{array}{l}\text { Number } \\
\text { Tumor appearance after injection }\end{array}$ & 4 & 4 \\
3 weeks & $4(100)$ & $0(0)$ \\
4 weeks & $4(100)$ & $4(100)$ \\
6 weeks & $4(100)$ & $4(100)$ \\
\hline
\end{tabular}

Table II. Comparison of tumor appearance between two groups due to differences in bisphosphonate use.

\begin{tabular}{lccc}
\hline & $\begin{array}{c}\text { Control } \\
\text { group }\end{array}$ & $\begin{array}{c}\text { Bisphosphonate } \\
\text { group }\end{array}$ & $p$-Value \\
\hline Bone destruction rate & & & \\
4 weeks after injection $(\%)$ & $12.9 \pm 6.7$ & $11.6 \pm 8.8$ & 0.725 \\
6 weeks after injection $(\%)$ & $26.6 \pm 9.9$ & $16.5 \pm 11.5$ & 0.040 \\
Tumor weight $(\mathrm{g})$ & $6.1 \pm 1.5$ & $7.0 \pm 2.1$ & 0.300 \\
Tumor volume $\left(\mathrm{mm}^{3}\right)$ & $2982 \pm 1736$ & $2899 \pm 1383$ & 0.900 \\
\hline
\end{tabular}

Values are expressed as frequencies and proportions of patients or means \pm standard deviations with ranges.

to reduce bone metastasis in breast cancer patients with a high risk of bone metastases (22). The effect of ZOL on bone lesions has been widely reported (23-24), but its effect on the local tumor itself has been questioned in some areas $(19,25)$. In this study, we used a new bone metastasis model to investigate the effects of $\mathrm{ZOL}$ on tumor lesions and bone metastatic lesions. Because ZOL is effective to administer as early as possible after tumor cell inoculation (19), we administered ZOL only 2 weeks post-injection. Consequently, 
bone destruction 6 weeks after tumor cell implantation was significantly suppressed in the ZOL group, suggesting that early administration of ZOL may inhibit local bone metastatic lesions in our model. This means that the new model is noninferior to the systemic model in terms of determining the efficacy of zoledronic acid and suggests that it could be useful for determining the efficacy of drug therapy. There was no significant difference in tumor weight or volume in the right thigh. The direct effect of ZOL on tumors could not be identified in this study and remains to be determined, even though ZOL may inhibit tumor-induced bone destruction by suppressing osteoclasts $(13,25)$.

One limitation of this study is that the mechanism of metastasis is not physiological. As it is obviously difficult to consistently generate tumors at fixed sites and be able to study the therapeutic effects of drugs on bone metastases, a local bone metastasis model is also necessary. Taken together, the animal model established in this study could be considered very useful in this regard.

In conclusion, we succeeded in creating a local bone metastasis model using E0771 breast cancer cells in C57BL/6 mice, which could be easily raised. This model may become one of the most effective models for evaluating new therapies for local bone metastasis in the future.

\section{Conflicts of Interest}

The Authors have no conflicts of interest directly relevant to the content of this article.

\section{Authors' Contributions}

All Authors were involved in the planning and revising for this research. SR, TH and $\mathrm{NH}$ raised experimental animals and administered drugs. SR analyzed the raw data, wrote this dissertation. HM, KY, KD and MN reviewed this dissertation.

\section{References}

1 Bray F, Ferlay J, Soerjomataram I, Siegel RL, Torre LA and Jemal A: Global cancer statistics 2018: GLOBOCAN estimates of incidence and mortality worldwide for 36 cancers in 185 countries. CA Cancer J Clin 68(6): 394-424, 2018. PMID: 30207593. DOI: $10.3322 /$ caac. 21492

2 Ferlay J, Soerjomataram I, Dikshit R, Eser S, Mathers C, Rebelo M, Parkin DM, Forman D and Bray F: Cancer incidence and mortality worldwide: sources, methods and major patterns in GLOBOCAN 2012. Int J Cancer 136(5): E359-E386, 2015. PMID: 25220842. DOI: 10.1002/ijc.29210

3 Cancer Registry and Statistics. Cancer Information Service, National Cancer Center, Japan (Vital Statistics of Japan) 2019. Available at: https://www.ncc.go.jp/en/cis/divisions/stat/index.html [Last accessed on December 16, 2021]

4 Allemani C, Matsuda T, Di Carlo V, Harewood R, Matz M, Nikšić M, Bonaventure A, Valkov M, Johnson CJ, Estève J, Ogunbiyi OJ, Azevedo E Silva G, Chen WQ, Eser S, Engholm
G, Stiller CA, Monnereau A, Woods RR, Visser O, Lim GH, Aitken J, Weir HK, Coleman MP and CONCORD Working Group: Global surveillance of trends in cancer survival 2000-14 (CONCORD-3): analysis of individual records for 37513025 patients diagnosed with one of 18 cancers from 322 populationbased registries in 71 countries. Lancet 391(10125): 1023-1075, 2018. PMID: 29395269. DOI: 10.1016/S0140-6736(17)33326-3

5 The Editorial Board of the Cancer Statistics in Japan (2017). Cancer statistics in Japan 2016. Foundation for Promotion of Cancer Research, Tokyo. Available at: https://ganjoho.jp/data/reg_ stat/statistics/brochure/2016/cancer_statistics_2016_pre_E.pdf [Last accessed on December 16, 2021]

6 Siegel RL, Miller KD and Jemal A: Cancer statistics, 2017. CA Cancer J Clin 67(1): 7-30, 2017. PMID: 28055103. DOI: 10.3322/caac. 21387

7 Lelekakis M, Moseley JM, Martin TJ, Hards D, Williams E, Ho P, Lowen D, Javni J, Miller FR, Slavin J and Anderson RL: A novel orthotopic model of breast cancer metastasis to bone. Clin Exp Metastasis 17(2): 163-170, 1999. PMID: 10411109. DOI: 10.1023/a:1006689719505

8 Rosol TJ, Tannehill-Gregg SH, LeRoy BE, Mandl S and Contag $\mathrm{CH}$ : Animal models of bone metastasis. Cancer 97(3 Suppl): 748-757, 2003. PMID: 12548572. DOI: 10.1002/cncr.11150

9 Simmons JK, Hildreth BE 3rd, Supsavhad W, Elshafae SM, Hassan BB, Dirksen WP, Toribio RE and Rosol TJ: Animal models of bone metastasis. Vet Pathol 52(5): 827-841, 2015. PMID: 26021553. DOI: 10.1177/0300985815586223

10 Wetterwald A, van der Pluijm G, Que I, Sijmons B, Buijs J, Karperien M, Löwik CW, Gautschi E, Thalmann GN and Cecchini MG: Optical imaging of cancer metastasis to bone marrow: a mouse model of minimal residual disease. Am J Pathol 160(3): 1143-1153, 2002. PMID: 11891210. DOI: 10.1016/S0002-9440(10)64934-6

11 Ewens A, Mihich E and Ehrke MJ: Distant metastasis from subcutaneously grown E0771 medullary breast adenocarcinoma. Anticancer Res 25(6B): 3905-3915, 2005. PMID: 16312045.

12 Yonemitsu K, Miyasato Y, Shiota T, Shinchi Y, Fujiwara Y, Hosaka S, Yamamoto Y and Komohara Y: Soluble factors involved in cancer cell-macrophage interaction promote breast cancer growth. Anticancer Res 41(9): 4249-4258, 2021. PMID: 34475044. DOI: 10.21873 /anticanres.15229

13 Wang L, Fang D, Xu J and Luo R: Various pathways of zoledronic acid against osteoclasts and bone cancer metastasis: a brief review. BMC Cancer 20(1): 1059, 2020. PMID: 33143662. DOI: $10.1186 / \mathrm{s} 12885-020-07568-9$

14 Hiraga T and Ninomiya T: Establishment and characterization of a C57BL/6 mouse model of bone metastasis of breast cancer. J Bone Miner Metab 37(2): 235-242, 2019. PMID: 29667006. DOI: $10.1007 / \mathrm{s} 00774-018-0927-y$

15 Haider MT, Holen I, Dear TN, Hunter K and Brown HK: Modifying the osteoblastic niche with zoledronic acid in vivopotential implications for breast cancer bone metastasis. Bone 66: 240-250, 2014. PMID: 24971713. DOI: 10.1016/j.bone.2014.06.023

16 Shiozawa Y, Pedersen EA, Havens AM, Jung Y, Mishra A, Joseph J, Kim JK, Patel LR, Ying C, Ziegler AM, Pienta MJ, Song J, Wang J, Loberg RD, Krebsbach PH, Pienta KJ and Taichman RS: Human prostate cancer metastases target the hematopoietic stem cell niche to establish footholds in mouse bone marrow. J Clin Invest 121(4): 1298-1312, 2011. PMID: 21436587. DOI: $10.1172 / J C I 43414$ 
17 Lu X, Mu E, Wei Y, Riethdorf S, Yang Q, Yuan M, Yan J, Hua Y, Tiede BJ, Lu X, Haffty BG, Pantel K, Massagué J and Kang Y: VCAM-1 promotes osteolytic expansion of indolent bone micrometastasis of breast cancer by engaging $\alpha 4 \beta 1$-positive osteoclast progenitors. Cancer Cell 20(6): 701-714, 2011. PMID: 22137794. DOI: $10.1016 /$ j.ccr.2011.11.002

18 Kuchimaru T, Hoshino T, Aikawa T, Yasuda H, Kobayashi T, Kadonosono T and Kizaka-Kondoh S: Bone resorption facilitates osteoblastic bone metastatic colonization by cooperation of insulin-like growth factor and hypoxia. Cancer Sci 105(5): 553559, 2014. PMID: 24597654. DOI: 10.1111/cas.12391

19 Jeong J, Lee KS, Choi YK, Oh YJ and Lee HD: Preventive effects of zoledronic acid on bone metastasis in mice injected with human breast cancer cells. J Korean Med Sci 26(12): 1569-1575, 2011. PMID: 22147993. DOI: $10.3346 / \mathrm{jkms} .2011 .26 .12 .1569$

20 Rivera J and Tessarollo L: Genetic background and the dilemma of translating mouse studies to humans. Immunity 28(1): 1-4 2008. PMID: 18199409. DOI: 10.1016/j.immuni.2007.12.008

21 Werbeck JL, Thudi NK, Martin CK, Premanandan C, Yu L, Ostrowksi MC and Rosol TJ: Tumor microenvironment regulates metastasis and metastasis genes of mouse MMTV-PymT mammary cancer cells in vivo. Vet Pathol 51(4): 868-881, 2014. PMID: 24091811. DOI: 10.1177/0300985813505116

22 Coleman R, Cameron D, Dodwell D, Bell R, Wilson C, Rathbone E, Keane M, Gil M, Burkinshaw R, Grieve R, BarrettLee P, Ritchie D, Liversedge V, Hinsley S, Marshall H and AZURE investigators: Adjuvant zoledronic acid in patients with early breast cancer: final efficacy analysis of the AZURE (BIG 01/04) randomised open-label phase 3 trial. Lancet Oncol 15(9): 997-1006, 2014. PMID: 25035292. DOI: 10.1016/S14702045(14)70302-X
23 Dammerer D, Blum P, Krappinger D and Keiler A: Common pitfalls in the management of bone metastasis of the extremities - a current concept and systematic review of the literature. Anticancer Res 41(10): 4665-4672, 2021. PMID: 34593414. DOI: 10.21873 /anticanres. 15280

24 Heymann PGB, Henkenius KSE, Ziebart T, Braun A, Hirthammer K, Halling F, Neff A and Mandic R: Modulation of tumor cell metabolism by laser photochemotherapy with cisplatin or zoledronic acid in vitro. Anticancer Res 38(3): 12911301, 2018. PMID: 29491052. DOI: 10.21873/anticanres.12351

25 Wang CY, Yang TT, Chen CL, Lin WC and Lin CF: Reactive oxygen species-regulated glycogen synthase kinase- $3 \beta$ activation contributes to all-trans retinoic acid-induced apoptosis in granulocyte-differentiated HL60 cells. Biochem Pharmacol 88(1): 86-94, 2014. PMID: 24406248. DOI: 10.1016/j.bcp.2013.12.021

Received October 26, 2021

Revised December 3, 2021

Accepted December 16, 2021 